\title{
Africa urged to create more fish farms
}

Fisheries experts are this week meeting the leaders of 25 African countries in Abuja, Nigeria, to call for urgent investment in aquaculture across the continent.

Africa's rapidly rising population means that it will need to produce significantly more fish to provide the same amount of food per head as it does now. But wild fish stocks in the continent are already on the verge of destruction.

The warning comes from the World Fish Center, an international research organization based in Malaysia, which has carried out a series of investigations into the state of Africa's fisheries. It finds that Africa is the only region in the world where per capita fish supplies are falling.

In Africa, only Egypt has developed aquaculture fast enough to match population growth, says Daniel Jamu of the World Fish Center. "The rest of Africa still has a long way to go."

The situation is especially serious in subSaharan Africa, where the per capita fish supply dropped from 9 kilograms a year in 1973 to 6.6 kilograms a year in 2001. Worldwide, that number increased from 12 to 16 kilograms a year over the same time period.

Fish is one of the most important sources of nutrition for Africans - it is much cheaper than meat, and almost $30 \%$ of the 690 million people in sub-Saharan Africa rely on it as the main part of their diet.

A third of sub-Saharan Africans are already undernourished: vitamin A deficiency contributes to the deaths of around half a million children each year and up to 20,000 women die annually from iron deficiency. Doing nothing about fish production would make these problems much worse, says Patrick Dugan, deputy director-general of the World Fish Center.

To maintain current consumption levels as the population rises, sub-Saharan Africa will need $32 \%$ more fish by 2020 , says Dugan. Wild fish stocks could collapse if fished any harder — in some areas, such as Lake Malawi, that is already happening. So most of the increase will have to come from fish farms. This means that sub-Saharan Africa would need to produce 3.6 times as many fish from aquaculture by 2020 as it does now - which would require the construction of thousands of freshwater ponds.

At least eight of the governments attending the Abuja meeting, including Kenya, Uganda and Malawi, are expected to sign a declaration on 25 August calling for help from the international community. Dugan says that US $\$ 30$ million every five years should be enough to support an annual 10\% increase in fish-farm output. The idea is that manual labour should be sufficient to dig the ponds, and the fish living in them can be fed with organic waste from the farmers' gardens.

The United States, Canada, Britain, Norway, Germany and Japan are already supporting similar efforts in countries such as Niger, Malawi and Uganda, says Richard Mkandawire, agricultural adviser for the New Partnership for Africa's Development, a continent-wide development initiative set up by the African Union. But he says he hopes that the conference will lead to increased efforts. "We see this meeting as a turning point for the revival of African fisheries as well as aquaculture development," he says.

Andreas von Bubnoff 